KTI/IE Discussion Papers 2005/13

Institute of Economics Hungarian Academy of Sciences

KTI/IE Discussion Papers are circulated to promote discussion and provoque comments. Any references to discussion papers should clearly state that the paper is preliminary. Materials published in this series may subject to further publication.

\section{Network Asymmetries and Access Pricing in Cellular Telecommunications}

Author: Viktória KOCSIS, Corvinus University of Budapest and Tinbergen Institute (Amsterdam)

E-mail: viktoria.kocsis@gmail.com

ISSN 1785-377X

ISBN 9639588563

Published by the Institute of Economics Hungarian Academy of Sciences Budapest, 2005 
MT-DP. 2005/13.

KOCSIS VIKTÓRIA

A HÁLÓZATOK KÖZÖTTI ASZIMMETRIA HATÁSA

A MOBILSZOLGÁLTATÓK VÉGZŐDTETÉSI DÍJÁRA

\section{Összefoglaló}

A cikk a mobil távközlés és az arra jellemzö kétirányú hozzáférés (hivásvégzödtetés) aszimmetrikus piacát elemzi piacszerkezeti modellek segitségével. Megvizsgálja, hogy aszimmetrikus helyzetben a szabályozás által elöirt költségalapú végzödtetési dij jóléti szempontból kivánatos megoldás-e, s ha igen milyen feltételek mellett. A 90-es évek végén megjelent szimmetrikus piacot feltételezö irodalomban található modellek fogyasztói hüséggel és a vállalatok eltérö költségszerkezetével való kiegészitése révén arra az eredményre jutottunk, hogy a vállalatok bármely ársémája mellett a vállalatok egyensúlyi profitja és a jólét sem független a végzödtetési dijtól. Vállalati szempontból a végzödtetési díj az összejátszás eszköze lehet. A fogyasztói többlet szempontjából a belépéshez közeli helyzetekben a végzödtetési költségnél magasabb, érett piacon a költségalapú vagy annál alacsonyabb végzödtetési dij kedvezőbb.

Kulcsszavak: hálózatok összekapcsolása, nem-tökéletes verseny, aszimmetrikus vállalatok, végzödtetési díj 


\title{
Network Asymmetries and Access Pricing in Cellular Telecommunications*
}

\author{
Viktória Kocsis ${ }^{\dagger}$
}

August 2005

\begin{abstract}
Network shares and retail prices are not symmetric in the telecommunications market with multiple bottlenecks which give rise to new questions of access fee regulation. In this paper we consider a model with two types of asymmetry arising from different entry timing, i.e. a larger reputation for the incumbent and lower cost of servicing for the entrant as a result of more advanced technology. As a result firms have divergent preferences over the access fee. In case of linear and non-linear prices the access fee might still act as the instrument of collusion, but only if a side-payment is permitted which is generally welfare decreasing. Moreover, in contrast with the European regulatory framework, the access fee on the basis of termination cost might not necessarily be a socially preferable solution.
\end{abstract}

JEL Classification: L11, L13, L51, L96

Keywords: cost asymmetry, brand loyalty, imperfect competition, network interconnection, access fee

\section{Introduction}

Over the last decade, the deregulation of telecommunications - formerly seen as a natural monopoly - plays an important role within policy and in economic literature. In this paper we focus on mobile telephony, particularly in the EU, which operated as a monopoly until the early 1990s and since then has functioned as an oligopoly ${ }^{1}$. At the beginning of the millennium a new framework for communications networks was introduced which was designed to harmonize European regulation in order to reduce entry barriers and facilitate effective competition for, the benefit of consumers. Under the new regulatory regime, each country is required to establish a national regulatory authority to monitor competition in communications markets and to define the relevant market segments. Furthermore they are to decide whether an operator has significant

\footnotetext{
*Accepted in Tinbergen Institute Discussion Paper Series. The author thanks Mark Armstrong, Gergely Csorba, Ferenc Forgó, András Gömöri and Maarten Janssen for their comments and recommendations. The paper has also benefited from the presentations at the Tinbergen Institute, at the Frankfurt Summer School on Digital Pricing, at the Institute of Economics of Hugarian Academy of Sciences and my home university.

${ }^{\dagger}$ Corvinus University of Budapest and Tinbergen Institute. Address: Tinbergen Institute, Roetersstraat 31, 1018 WB Amsterdam, The Netherlands. E-mail: viktoria.kocsis@gmail.com

${ }^{1}$ For the evolution of mobile telecommunications in Europe see Gruber (2001) and Gruber and Verboven (2001).
} 
market power (SMP) in a particular segment and to assess the appropriate regulatory obligations. On the basis of an EU communications directive on access and interconnection, the wholesale mobile voice call termination has already been defined as a relevant market in most of the European countries, since each operator is a monopolistic provider for its respective bottleneck and charges an access fee for usage ${ }^{2}$. In the resent years, the access fee for call termination was freely negotiated between firms; however under the new regulatory framework the termination charge set by the SMP operators is controlled. Currently transitional methodologies are used and within a few years, an access fee regulated on the basis of long-run incremental cost (LRIC) will be introduced. The LRIC is a forward-looking methodology which measures the additional cost an operator incurs to provide termination on its network.

Several asymmetries can be observed on the telecommunications market. These asymmetries require an individual consideration of each firm with regard to regulation. In this paper, we focus on two types of asymmetry. Liberalizing the telephony market has provided opportunity for new entry and as a consequence resulted in asymmetries among firms entering the market early (incumbent) and late (entrant). The reasons for this may be as follows: first, the entrant had the opportunity to introduce a more recent technology which implies a lower cost of servicing (i.e. supply side advantage). On the other hand the incumbent who entered the market earlier may gain an extra advantage because of reliability or reputation for quality, realized in the form of extra utility for those consumers who wished to subscribe for the incumbent's services (i.e. demand side advantage or brand loyalty). This extra utility can be reckoned as a switching cost because if a consumer subscribed to the incumbent wants to switch network, he has to face additional costs like the administrative cost of switching or the reimbursement of discounts resulting from a longer contract or buying a new cellular device. In the presence of this type of cost, a consumer is willing to change between networks only if the additional cost of switching is smaller than the extra surplus gained from the other firm's lower price. However, because of the learning process of consumers about the quality of the operators, and as a consequence of competition, the additional incentives to innovate and to reduce costs, the brand loyalty and the cost advantage might diminish over time which may result in more symmetric competition.

Thus all these asymmetries, together with rapidly developing technologies call for a reconsideration of the role of the regulatory mechanism. The following questions arise: is the cost-based access fee tenable, or do other ways of asymmetric or symmetric access price regulation seem reasonable? What is the effect of access price regulation on firms' profit and on consumer surplus?

In this paper, we seek to find the answer to these questions in the presence of brand loyalty, cost asymmetry and linear demand. We formalize a market with two firms competing for consumers with horizontally differentiated products. The firms are interconnected: they have to pay a two-way access fee for call termination; each firm maximizes its profit charging retail price(s) simultaneously and non-cooperatively. First we present Armstrong's (2002) model as a benchmark case, however we focus more on the supply side (cost)

\footnotetext{
${ }^{2}$ The most pertinent and normative European (tele)communications authority is Ofcom (formerly Oftel) in the UK. For more details in accordance with the EU harmonization across cellular markets see Ofcom (2004).
} 
asymmetry, the equilibrium conditions and the comparative statics. The most relevant paper related to cost asymmetry is Armstrong (2002) in which the author considers a market where each consumer makes one unit of calls to every other consumer. He also assumes that the advantage of the incumbent resulting from its reputation outweighs the cost advantage of the entrant. In this case the incumbent always has a larger market share. As a policy implication he derives that the firms have divergent preferences over the access fee. The total industry profit changes in the same direction as the incumbent's larger profit, so that a side payment to the entrant might compensate for an access fee which is against the entrant's interest. The larger the retail price, the smaller the consumer surplus; however, because of the inelastic demand, the increment in the industry profit is equal to the decrease in the consumer surplus, thus resulting in welfare-neutrality of the equilibrium.

To complement Armstrong's results, in case of extremely large asymmetry we find that the firm which has larger advantage over the other firm can corner the market and drive out its rival. In contrast to Armstrong's case, if the cost asymmetry exceeds the demand side asymmetry, as a result of an access fee change, the industry profit varies with the entrant's profit, creating the opportunity for the entrant to set its access fee larger than its marginal termination cost and compensate the incumbent for its profit loss. Consumer surplus varies opposite to the industry profit and welfare remains unchanged.

In the second part of the paper, we extend this model to linear demand for telephony consumption and to uniform linear retail prices. Since the access profits do not cancel out, we find quartic and asymmetric first derivatives, therefore the main results arise from simulations. The equilibrium exists if the difference between access fees is sufficiently small and the networks are weak substitutes. For strong substitution, price competition is unstable since the firms try to undercut each other more intensively and so corner the market. Studying the effect of different access fees under strong supply side asymmetry, we find similar results to the unit consumption case; however, the welfareneutrality property of the equilibrium no longer holds true: welfare generally varies with consumer surplus. For stronger brand loyalty, firms prefer the same access fee difference, possibly resulting in a negative access mark-up for the entrant.

Finally, we extend the model to the case of competition in two-part tariffs, where each firm sets a uniform per-minute charge and a fixed fee at the same time. Firms set their per-minute prices equal to their perceived marginal costs and compete for the consumers with fixed fees, while trying to extract as much of the consumer surplus as possible. We find that independently of asymmetry, the firms' preferences over the access fee are divergent, and therefore they might negotiate a termination charge which is preferable for one of the firms, since this also increases industry profit. In the case of small cost asymmetry, a positive access mark-up for the entrant favors both the entrant itself and consumers. However for larger cost asymmetry the rise in access fee lowers the consumer surplus.

This paper is an extension of the common symmetric models of network interconnection and competition. The first articles published on this topic are Armstrong (1998) and Laffont et al. (1998a), in which the authors analyze the problem of two-way access pricing in the set up of a symmetric cost structure, 
uniform pricing and reciprocal (equal) access fee. They claim that for small access markup and poor network substitution, there is a unique, symmetric and stable equilibrium, while on the other hand, if network services are strong substitutes, then no equilibrium exists. The main and principally cited results of their articles are that (i) under linear retail pricing, the price increases in the access fee and therefore, the access fee may be an instrument of collusion, and (ii) under two-part tariffs, the profit is independent of the access fee. If termination-based price discrimination is considered in the model, as Laffont et al. (1998b) shows, then under linear prices it is only possible for the access fee to be the instrument of collusion in the case of weak substitution; however in the case of two-part tariffs, firms will agree on a cost-based access fee thus bringing price discrimination to an end.

The profit-neutrality property is confirmed in a more general set up by Dessein (2004) and Hahn (2004), who assume consumer heterogeneity in terms of demand for calls and calling pattern.

In Carter and Wright (1999), Carter and Wright (2003) and Peitz (2005) the authors consider an asymmetric market in the presence of brand loyalty and leave the other segments (for instance costs) symmetric. In the case of reciprocal access fees, that is the same access fee for each firm, Carter and Wright state that if the market shares are symmetric, the firms are indifferent with regard to the access fee. Otherwise the firm with brand loyalty prefers a cost-based access fee and if brand loyalty is sufficiently strong, the other firm has the same preference. Moreover the cost-based access fee is in most cases socially optimal. Peitz emphasizes the use of a non-reciprocal access fee, since an asymmetric access price regulation which allows positive access mark-up for the entrant can be socially more desirable: it favors the entrant and increases consumer surplus at the same time.

In de Bijl and Peitz (2002) and de Bijl and Peitz (2004), the authors focus on the same type of asymmetry although they analyze the market in a dynamic set up and use simulation to derive policy implications. They find that independently of the type of access price regulation, the asymmetry among firms lessens over time; the entrant's profit and the consumer surplus increase and finally a symmetric equilibrium emerges. In their (2004) article, they extend their model with asymmetrical marginal costs and derive similar results from the simulations to those they found previously.

The structure of the present paper is as follows. In Section 2, we define all the terms and conditions which are used in the paper and then present Armstrong's model as a benchmark case. In Section 3, we extend his model to competition with uniform linear tariffs under linear demand for calls; in Section 4, we derive the equilibrium for non-linear tariffs. In Section 5, we conclude. The proofs are shown in Appendix A and simulation results in Appendix B.

\section{Benchmark case: unit consumption}

First we present the stylized model from Armstrong (2002), in which he assumes a market with unit telephony consumption and seeks to find arguments in the interest of implementing a non-reciprocal access fee. Since in his article 
Armstrong considers a market in which demand side asymmetry outweighs supply side asymmetry and these asymmetries cannot show extreme values, in this section we focus more on supply side asymmetry, the conditions and comparative statics of the equilibrium. Moreover the proof of the equilibrium will be shown in the Appendix.

Furthermore, this section defines the most important terms and introduces the assumptions used in this paper; other versions presented will be expressed in terms of deviation from this set up.

\subsection{Cost structure and access fee}

Consider a market with two networks indexed by $i=1,2$. We name firm 1 as incumbent and firm 2 as entrant to make a distinction according to their reputation and costs, though we analyze a simultaneous move game. To avoid Bertrand competition and to measure the effect of different pricing schemes on market shares, we assume that firms compete for consumers by means of a horizontally differentiated service on a segment $[0,1]$, that is we consider the model for product differentiation a la Hotelling (1929). We assume maximal product differentiation, namely the firms are located at the two ends of the segment $\left(x_{1}=0, x_{2}=1\right)$. Each firm incurs three types of costs:

(i) connection independent cost. For instance this could be, the fee for a license or the cost of building-up and improving facilities. These costs will be considered in the model as sunk costs.

(ii) connection dependent but traffic independent cost. This is the fixed $\operatorname{cost} f_{i}$ of serving a consumer, and without loss of generality we assume that the fixed cost is the same for both firms, i.e. $f_{1}=f_{2}=f$.

(iii) traffic dependent cost. This is a unit cost $c_{i O}$ of originating and $c_{i T}$ of terminating a call. For simplicity we assume that $c_{i O}=c_{i T}=c_{i}^{0}$. We define the cost asymmetry in the level of marginal costs which is the difference in termination costs. Assume that firm 2, the entrant, is more efficient, i.e.

$$
0 \leq c_{2}^{0}<c_{1}^{0}
$$

Denote $C_{i} \equiv 2 c_{i}^{0}+f_{i}$ and $\Delta^{c} \equiv c_{2}^{0}-c_{1}^{0}$.

The networks are interconnected which means that if a consumer subscribed to a firm originates a call, this call may be terminated on the rival firm's network. In this case, the firm has to purchase access to ensure that its subscribers are able to call all consumers independently of service provider and therefore, the firm has to pay an access fee for each unit call terminated on the rival's network. In the model network $i$ charges a per-unit access charge $\tau_{i}$ for terminating its rival's off-net call and pays $\tau_{j}$ per-unit fee to network $j$ for terminating its off-net call on network $j$. We assume that the access fee is not a decision variable of the firm and can be determined by negotiation among the firms or by the government. Hereafter denote $\Delta^{\tau} \equiv \tau_{2}-\tau_{1}$.

On the basis of the above definitions the unit cost of a call depending on its termination can be determined. If a call is originated and terminated on the same network (i.e. on-net call), say in network $i$, the total unit cost is equal to $c_{i} \equiv 2 c_{i}^{0}$. However if a call is originated in network $i$ but terminated on 
network $j$ (i.e. off-net call), network $i$ incurs a unit cost of $c_{i}^{0}+\tau_{j}$, and if a call of network $j$ is terminated on network $i$, network $i$ 's unit cost is equal to $c_{i}^{0}-\tau_{i}$.

\subsection{Demand structure and consumer surplus}

A consumer decides about connecting to a network, and then consumes one unit of the service independently of price, or in other words, the demand for consumption is inelastic. Consumers are homogeneous in the sense that each consumer gains the same fixed surplus of being connected $\left(v_{0}\right)$. On the other hand, the consumers are heterogeneous since they have different a priori preferences: a consumer values a service more when it is 'closer' to his preference. Let $x$ denote the characteristic (location) of the consumer on the segment $[0,1]$ and assume that the consumers are uniformly distributed on this segment. As the preference of a consumer is different from the characteristics of service supplied by the networks (i.e. different location), the consumer has to pay 'transportation cost' $(t>0)$ which cost measures the disutility of not being a consumer of the ideal firm. The larger $t$, the more differentiated the networks are, that is the less strong the substitutability between networks. We assume that $t$ is the same for all consumers and the total transportation cost is a linear function of the distance.

Therefore the total utility of a consumer is

$$
v_{0}-t\left|x-x_{i}\right|+t \beta_{i}-p_{i},
$$

where

1. $v_{0}$ is assumed to be high enough to provide full consumer participation in the market, in case of unit consumption that is

$$
v_{0}>t\left(2-\frac{\beta_{1}+\beta_{2}}{2}\right)+\frac{C_{1}+C_{2}}{2}-\frac{\Delta^{\tau}}{3}\left(\beta+\frac{2 \Delta^{c}}{t}\right)
$$

2. the second term indicates the total transportation cost since the consumer travels a distance of $\left|x-x_{i}\right|$, where $x_{i}$ denotes the location of the firm which can be 0 or 1

3. $\beta_{i}$ is the extra utility a consumer receives when subscribed to network $i$ (i.e. brand loyalty or switching cost). Assume that $\beta \equiv \beta_{1}-\beta_{2}>0$, that is that the incumbent has stronger reputation on the market. The second and the third terms together measure the consumer's network specific utility.

4. $p_{i}$ denotes the uniform retail price set by firm $i$. A price is uniform if a company does not differentiate prices depending on which network a call is terminated on.

Since consumers are uniformly distributed on $[0,1]$, in order to find the optimal proportion of consumers in each network, we aim at finding the consumer who is indifferent to being a subscriber of network 1 or being one of network 2 . A consumer located in $\alpha$ is indifferent to the networks if

$$
v_{0}-t \alpha+t \beta-p_{1}=v_{0}-t(1-\alpha)-p_{2} .
$$


Then $\alpha$, the market share of firm 1 , is equal to

$$
\alpha\left(p_{1}, p_{2}\right)=\frac{1+\beta}{2}+\sigma\left(p_{2}-p_{1}\right)
$$

where $\sigma=\frac{1}{2 t}$ is the measure of substitution. The inverse ratio between $\sigma$ and $t$ means that the larger the transportation cost, i.e. the more 'painful' it is to be further from the ideal network, the weaker the substitution between the networks. Denote $\alpha_{i}$ firm $i$ 's market share; in addition we know that $\alpha_{i}$ is a function of the prices and $\alpha_{1}+\alpha_{2}=1$. When the prices are equal, if $0 \leq \beta \leq 1$ the market shares are non-negative; if $\beta=0$, then the market is symmetric; if $\beta>0$, then the incumbent has a larger market share, and in the extreme case of $\beta=1$, the entrant has no chance to extract any subscriber from the incumbent.

In the model, we use the assumption of balanced calling pattern which means that every consumer initiates the same number of calls he receives. This implies that in case of homogenous consumers, the fraction of calls originating in a network which terminate on the other network is proportional to the latter network's market share.

\subsection{Price competition}

Before defining the firms' optimization problem, we illustrate the firms' benefits and costs in the next figure.

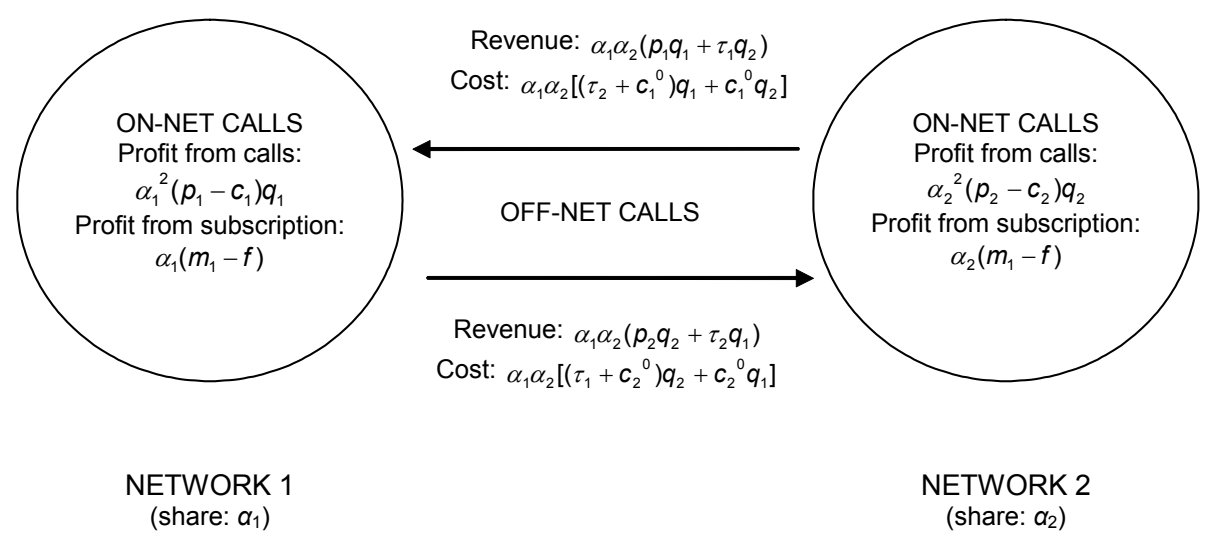

Figure 1. Costs and revenues in a market of interconnection and competition.

The figure indicates all the parameters and variables which are used in the most general model of this paper. In the current model each consumer buys one unit of call (that is $q_{1}=q_{2}=1$ ) and pays only price $p_{i}$ for it (that is $m_{i}=0$ exogenous). In the first extension the demand is linear $\left(q_{i} \geq 0\right)$ and firm $i$ sets a linear price $p_{i} \geq 0$ while $m_{i}=0$ exogenous. In the last model firm $i$ sets a two-part tariff so that its consumers have to pay a per-minute charge $p_{i} \geq 0$ and a fixed fee $m_{i} \geq 0$. As a result of balanced calling pattern and consumer homogeneity in terms of demand, firm $i$ originates the $\alpha_{i}^{2}$ share of on-net calls 
and the $\alpha_{i} \alpha_{j}$ share of off-net calls, and terminates the $\alpha_{i} \alpha_{j}$ share of off-net calls as well.

Since the access fee is given by negotiation or set by the government, we model the market as a noncooperative game in strategic form and seek to find a unique Nash-equilibrium ${ }^{3}$. There are two firms in the market $(i=1,2)$ with the previously described characteristics competing for consumers by choosing a price profile $s=\left(p_{1}, p_{2}\right)$. As it can be tracked from Figure 1, firm $i$ has the following profit function:

$$
\pi_{i}(s)=\underbrace{\alpha_{i}\left(p_{i}-C_{i}\right)}_{\text {retail profit }}+\underbrace{\alpha_{i} \alpha_{j}\left(\tau_{i}-\tau_{j}\right)}_{\text {access profit }}
$$

where the first part measures the retail profit from telephony consumption and the second part comprises benefits and costs derived from providing access to its rival and using its rival's facilities. Firm $i$ maximizes its profit function (1) by choosing a price $p_{i}$ given its rival's price $p_{j}$ and subject to

$$
\begin{aligned}
0 & \leq p_{i} \\
0 & \leq \alpha_{i} \leq 1, \quad i=1,2 . \\
0 & \leq \pi_{i}
\end{aligned}
$$

Unlike the symmetric models of telecommunications, the asymmetry in the profit function suggests that the equilibrium will not be symmetric. From the first order conditions of the profit maximization, one obtains the following Nash-equilibrium ${ }^{4}$.

\section{Proposition 1 If}

$$
\left|\Delta^{\tau}\right|<\frac{1}{2 \sigma},
$$

there exists an equilibrium which is unique, asymmetric and can be shared or cornered.

If

$$
|\lambda|<3,
$$

where $\lambda \equiv \beta+4 \sigma \Delta^{c}$, then the equilibrium is shared. Firm $i$ sets price $p_{i}^{*}$, gains market share $\alpha_{i}^{*}$ and profit $\pi_{i}^{*}$ which are the following:

$$
\begin{gathered}
p_{1}^{*}=\frac{1}{2 \sigma}+\frac{\beta}{6 \sigma}+\frac{2 C_{1}+C_{2}}{3}-\frac{\Delta^{\tau} \lambda}{3}, \\
p_{2}^{*}=\frac{1}{2 \sigma}-\frac{\beta}{6 \sigma}+\frac{2 C_{2}+C_{1}}{3}-\frac{\Delta^{\tau} \lambda}{3}, \\
\alpha_{1}^{*}=\frac{1}{2}+\frac{1}{6} \lambda \\
\pi_{i}^{*}=\left(\alpha_{i}^{*}\right)^{2}\left[\frac{1}{\sigma}+\tau_{i}-\tau_{j}\right] .
\end{gathered}
$$

For large cost difference and strong substitution (that is $\lambda<-3$ ) the entrant and for strong brand loyalty (that is $\lambda>3$ ) the incumbent corners the market, sets the above equilibrium price and serves the whole market.

\footnotetext{
${ }^{3}$ We seek to find the Nash-equilibrium which can be defined as in Vega-Redondo (2003), p. 39 .

${ }^{4}$ The proof is given in Appendix A.
} 
The proposition claims that the equilibrium exists and is unique if $\left|\Delta^{\tau}\right|<$ $1 / 2 \sigma$; under this condition the second order conditions hold and therefore the profit functions are strictly quasi-concave. Moreover, we find that $0<r_{i}^{\prime}(\cdot)<1$ and $r_{i}^{\prime}(\cdot)$ is constant which provides the single crossing property of the reaction curves $r_{i}\left(p_{j}\right)$. In accordance with this condition, the equilibrium exists if the substitution between the networks is weak and the difference between the access fees is small enough. The underlying intuitions are similar to the symmetric model of Armstrong (1998) and Laffont et al. (1998a).

Armstrong in his 2002 model assumes that $\lambda>0$, which means that the incumbent's advantage coming from larger brand loyalty is larger than the entrant's cost advantage. Moreover he dispenses with extreme asymmetries by assuming that $\lambda<3$. The current analysis considers the demand and supply side asymmetries, and examines the effect of extreme asymmetries on the equilibrium.

The incumbent always sets a higher price because it faces higher termination cost and benefits from stronger brand loyalty. However, since each firm has an advantage over the other, if its advantage is strong enough, it can set a price so as to drive out the other firm from the market. If brand loyalty is very strong $(\beta>>3)$ or the cost difference is large and the substitution is strong $\left(4 \sigma\left|\Delta^{c}\right|>>3\right)$, a monopoly outcome emerges: in the first case the incumbent corners the market, in the latter the entrant. These conditions are realized by extremely high parameter values which can only emerge in an infant market. In general, when brand loyalty is less strong $(\beta<3)$ or the cost difference is lower and the networks are weaker substitutes $\left(4 \sigma\left|\Delta^{c}\right|<3\right)$, a shared-market equilibrium emerges. Henceforth we will eliminate the extreme parameter values and focus on the shared-market outcomes.

Before generalizing the results, two special cases will be considered. If the cost difference is equal to zero (that is firms are symmetric), in spite of its higher price the incumbent receives larger market share, since from (2), (3) and (4)

$$
\begin{aligned}
& \Delta^{p} \equiv p_{2}-p_{1}=-\frac{\beta}{3 \sigma}<0, \\
& \Delta^{\alpha} \equiv \alpha_{2}-\alpha_{1}=-\frac{\beta}{3}<0 .
\end{aligned}
$$

If the access fees are set on the basis of cost, the incumbent receives higher profit. However if the entrant is allowed to set an access fee larger than the termination cost to compensate for its disadvantage, it might occur that the difference in access profits exceeds the difference in retail profits; therefore the entrant gains higher profit.

In the special case of zero brand loyalty, the entrant sets a lower price and attracts more subscribers:

$$
\begin{gathered}
\Delta^{p}=\frac{2 \Delta^{c}}{3}<0, \\
\Delta^{\alpha}=-\frac{4 \sigma \Delta^{c}}{3}>0 .
\end{gathered}
$$

Following the same train of thought as before, in the case of cost-based access fee the entrant receives higher profit; although if the incumbent may set an access fee higher than its cost, it can realize higher profit. 
In general, when $\Delta^{c}>0$ and $\beta>0$, the entrant's price is lower since

$$
\Delta^{p}=-\frac{\beta}{3 \sigma}+\frac{2 \Delta^{c}}{3}<0,
$$

however the market shares and the profits vary according to the intensity of asymmetry; from (4):

$$
\Delta^{\alpha}=-\frac{\lambda}{3}
$$

thus

$$
\Delta^{\alpha}<0 \Leftrightarrow \lambda>0 .
$$

The condition $\lambda>0$ holds if brand loyalty is strong and for a given substitution $\Delta^{c}$ is small or for a given $\Delta^{c}$ the services are weak substitutes. As a result, the incumbent obtains more subscribers. On the other hand, if $\beta$ is small and for a given substitution the cost difference is large or the networks are strong substitutes, then $\lambda<0$, causing a larger market share for the entrant. As for the firms' profit, the difference depends on the market shares and the access mark-up: the stronger the brand loyalty or the smaller the cost difference and the access mark-up, the more likely that the incumbent gets higher profit. Otherwise the entrant is better off.

\subsection{How access fee affects the equilibrium?}

Following Armstrong's idea, to derive a relation between the access fee, firms' preferences and social preference, we analyze the effect of $\Delta^{\tau}$ on the equilibrium prices and profits. As formula (5) shows, in an asymmetric market a firm with higher market share which charges a higher access fee gets higher profit. Since the market shares are independent of the access fee (see (4)), the larger $\Delta^{\tau}$, the better for firm 2 and the worse for firm 1 which implies that the firms have divergent preferences over the access fee. As for the whole industry, a marginal change in the industry profit $\left(\pi \equiv \pi_{1}+\pi_{2}\right)$ is equal to

$$
\frac{\partial \pi}{\partial \Delta^{\tau}}=\frac{\partial \pi}{\partial \tau_{2}}=\Delta^{\alpha}
$$

therefore if $\Delta^{\alpha}<0$, the industry prefers a smaller $\Delta^{\tau}$, otherwise a larger $\Delta^{\tau}$ is more favorable. If brand loyalty is strong, the incumbent has a higher market share and as a result industry profit is decreasing in $\Delta^{\tau}$. In a more symmetric market where brand loyalty is weaker and the cost difference dominates, the entrant has a higher market share. In this case, the total industry profit varies in the same direction as the entrant's profit: the larger $\Delta^{\tau}$, the larger the industry profit. Therefore in the first case the incumbent might compensate the entrant with a side-payment in favor of setting a lower difference in access fees, otherwise the entrant has the opportunity to choose a higher access fee and compensate the incumbent.

The change in consumer surplus also depends on brand loyalty and cost difference, but in the opposite way to before. Since

$$
\frac{\partial p_{i}}{\partial \Delta^{\tau}}=-\left(\beta+4 \sigma \Delta^{c}\right) \equiv-\lambda,
$$


if $\lambda>0$, then equilibrium prices are decreasing in $\Delta^{\tau}$ which favors consumers. Otherwise the prices are increasing, thus lowering consumer surplus. This result is intuitive since there is full consumer participation in the market. Moreover since there is full participation on the market, the change in industry profit is equal and opposite to the change in consumer surplus. Therefore the welfare, which is equal to profits plus consumer surplus, does not vary with the access fee. In other words, in case of unit consumption for a given market share the total welfare is constant and since market shares do not depend on the access fee, welfare is also independent of the access fee. The following proposition summarizes the above results ${ }^{5}$.

Proposition 2 Suppose that the incumbent is subject to cost-based access fee. The effect of a larger $\Delta^{\tau}$ is the following:

(i) Firms have divergent preference over the access fee. If brand loyalty is strong (that is $\lambda>0$ ), the incumbent's profit varies in the same direction as the industry profit which is decreasing in $\Delta^{\tau}$, meaning a lower access fee for the entrant. In this case the incumbent may compensate the entrant for a lower access fee. If the cost difference is large (that is $\lambda<0$ ), the industry profit varies with the entrant's profit, giving the opportunity to set a larger access fee and compensate the incumbent.

(ii) Consumer surplus varies in the opposite direction to industry profit.

(iii) Welfare remains unchanged.

\section{Linear demand and linear tariffs}

In this section, we extend the previous model to a model with linear demand for telephony consumption and seek an answer to the following questions: what is the effect of cost asymmetry and brand loyalty on the equilibrium and its properties? What are the preferences of the firms and the social planner over the access fee?

\subsection{Demand structure and consumer surplus}

Since we relax the assumption of unit consumption and extend it to a linear demand function, a consumer faces a two-step problem: in the first step he decides on whether to connect to a network and in the second step he chooses the amount of telephony consumption. We leave the first group of characteristics of consumers as it was set in subsection 2.2 , that is the fixed surplus $v_{0}$, the network specific surplus $\beta_{i}$ (and $\beta \equiv \beta_{1}-\beta_{2}>0$ ) and different a priori preferences with respect to the consumer's location $x$ and the 'traveling cost' $t$. Applying these assumptions, the total utility of a consumer subscribed to firm $i$ is equal to

$$
v_{0}-t\left|x-x_{i}\right|+t \beta_{i}+u(q)-p_{i} q,
$$

where the sum of the first three terms measures the utility of being connected (traffic independent surplus), and the sum of the last two terms measures the

\footnotetext{
${ }^{5}$ The proposition can be proved easily by the above argument.
} 
utility from telephony consumption (traffic dependent surplus): $u(q)$ is the utility from telephony consumption $q$ assumed to be the same for all consumers and $p_{i}$ denotes the uniform linear price of firm $i$.

We can solve the consumer's two-step problem by backward induction. In the second step, given the retail prices, a consumer decides about telephony consumption. His utility function is considered quadratic, i.e. ${ }^{6}$

$$
u(q)=q-\frac{q^{2}}{2},
$$

therefore his demand function for telephony consumption is linear:

$$
q(p)=1-p
$$

As a consequence, the variable net surplus gained from consumption is as follows:

$$
v(p)=\max _{q}\{u(q)-p q\}=\frac{(1-p)^{2}}{2} .
$$

In the first step a consumer chooses a network. The optimal network share of firms can be determined by finding a consumer, located in $\alpha$, who is indifferent between the networks, that is

$$
v_{0}-t \alpha+t \beta+v\left(p_{1}\right)=v_{0}-t(1-\alpha)+v\left(p_{2}\right) .
$$

Then $\alpha$, the network share of firm 1 , is

$$
\alpha\left(p_{1}, p_{2}\right)=\frac{1+\beta}{2}+\sigma\left[v\left(p_{1}\right)-v\left(p_{2}\right)\right]
$$

where $\sigma=\frac{1}{2 t}$ is the measure of substitution. Introduce the notation $v_{i} \equiv v\left(p_{i}\right)$, $q_{i} \equiv q\left(p_{i}\right)$ and denote $\alpha_{i}$ firm $i$ 's market share which is a function of the retail prices.

For a given $s=\left(p_{1}, p_{2}\right)$ strategy profile the total consumer surplus can be defined in the following way:

$$
S(s)=\alpha_{1} v_{1}+\alpha_{2} v_{2}-D\left(\alpha_{1}\right),
$$

where $D(\alpha)$ measures the average disutility originating from the difference between the a priori preferences of consumers and the characteristics of services offered by the networks. Or in other words, the function $D(\cdot)$ is the average traveling cost between the location of consumers and firms which is for any $\alpha$ equal to

$$
D(\alpha)=\frac{1}{2 \sigma}\left[\alpha \frac{\alpha}{2}+(1-\alpha) \frac{1-\alpha}{2}\right]=\frac{1}{2 \sigma}\left[\frac{\alpha^{2}+(1-\alpha)^{2}}{2}\right] .
$$

\footnotetext{
${ }^{6}$ We use a simple quadratic utility function because it fulfils the general assumptions; moreover it makes the analysis easier since a linear demand function can be derived from the first order condition of utility maximization. We might also set up a more general model using the utility function $u(q)=a q-b \frac{q^{2}}{2}$, however this generality does not modify the main results.
} 


\subsection{Price competition}

The basic characteristics of firms remain the same as were presented in subsection 2.1. We look for the Nash-equilibrium of a static game in which firms $(i=1,2)$ compete for consumers by setting a price profile $s=\left(p_{1}, p_{2}\right)$. As can be seen from Figure 1 and recalling that $m_{i}=0$, firm $i$ 's profit is equal to

$$
\pi_{i}(s)=\alpha_{i}\left[\left(p_{i}-c_{i}\right) q_{i}-f\right]+\alpha_{i} \alpha_{j}\left[\left(\tau_{i}-c_{i}^{0}\right) q_{j}-\left(\tau_{j}-c_{i}^{0}\right) q_{i}\right] .
$$

In the Nash-equilibrium, firm $i$ maximizes its profit function (6) according to its price $p_{i}$ given the rival's price $p_{j}$, subject to

$$
\begin{aligned}
& 0 \leq p_{i} \leq 1, \\
& 0 \leq \alpha_{i} \leq 1, \quad i=1,2 . \\
& 0 \leq \pi_{i}
\end{aligned}
$$

Since the access profit depends on $\alpha_{i} \alpha_{j} q_{i}$ which is a fifth-degree function of $p_{i}$, the first derivatives of the profit function are quartic, and therefore - and only in case of linear prices - it is not possible to find a closed form solution for the reaction functions and for the equilibrium prices. Moreover, the second derivatives are cubic which makes the specification of equilibrium conditions very complicated. To avoid this calculation problem, we ran simulations ${ }^{7}$, and from the results we derive conclusions about the existence of the equilibrium and about policy implications.

\subsection{Comparison and policy implications}

We find that for very large access fee difference and very strong substitution, there exists no equilibrium, which is a robust result of Armstrong (1998) and Laffont et al. (1998a).

Similarly to the unit consumption case, a firm with enormous advantage over the other firm might corner the market. Denote $\Delta^{v} \equiv v_{2}-v_{1}$. Monopoly equilibrium can emerge, if one of the following conditions holds:

$$
v_{1}-\frac{1-\beta}{2 \sigma} \geq v_{2} \Leftrightarrow \Delta^{v} \leq-\frac{1-\beta}{2 \sigma}
$$

or

$$
v_{1}+\frac{\beta}{2 \sigma} \geq v_{2}-\frac{1}{2 \sigma} \Leftrightarrow \Delta^{v} \geq \frac{1+\beta}{2 \sigma}
$$

In the first case the incumbent drives out the other firm from the market, in the second the entrant. Because of the same reason as in the benchmark case, the entrant always charges a lower price; therefore its consumers realize higher variable net surplus. Since $\Delta^{v}>0$, the first condition fulfils if $\beta>>1$, that is strong brand loyalty, and the second condition holds if for a given $\beta,\left|\Delta^{c}\right|$ is sufficiently large. The cornering conditions require extreme parameter values; therefore we will solely focus on the more general cases, namely the sharedmarket equilibria.

We can draw up other characteristics of the equilibrium. Equilibrium prices are decreasing in substitution between the networks, that is the stronger the

\footnotetext{
${ }^{7}$ For simulations we used Mathematica 5.0.
} 
substitution, the smaller the prices, which means that the stronger substitution stimulates competition, thus lowering firms' profit and causing smaller network share for the incumbent (the effect of brand loyalty becomes weaker and the effect of the cost difference becomes stronger). Moreover, from a welfare point of view, it is preferable to have more fierce competition in the market (see Figures 2 and 3 in Appendix B.1).

The further brand loyalty and the cost difference are from zero, the further the equilibrium is from the symmetric case. Since the two effects of different timing of entry are opposite, we need to separate them so as to compare the outcomes. As the data shows, the entrant's profit is generally higher than the incumbent's profit. For a given degree of brand loyalty, the smaller the cost difference, the larger the incumbent's profit and the smaller the entrant's profit, though the resultant is ambiguous just as is the change in consumer surplus and welfare. However for stronger brand loyalty, the equilibrium price difference becomes larger, and therefore the incumbent's market share and profit decrease, while the entrant's profit increases. The consumer surplus varies opposite to the industry profit. In a more asymmetric market the welfare increases with the industry profit; however in a more symmetric market the effect of $\Delta^{\tau}$ on consumers surplus is stronger than on the industry profit, thereby causing higher welfare (see Figures 4 and 5 in Appendix B.1).

The most important and most controversial point in the analysis is the determination of the access fee. As we discussed in the introduction, the relevant questions are whether to impose cost-based access fee regulation, or allow freely negotiated access fee and for the less efficient firm to set an access fee containing a positive mark-up. As before, the main results for policy makers are derived from simulations (see Figures 6-11 in Appendix B.2).

Let us use the difference in access fees $\left(\Delta^{\tau}\right)$ for the policy implications, and assume that the incumbent is subject to a cost-based access fee. When brand loyalty is relatively small compared to the cost difference, that is to say strong supply side asymmetry is present, then the equilibrium prices increase in $\Delta^{\tau}$. As a consequence, the net surplus a consumer receives decreases, thus lowering consumer surplus (see Figures 6 and 7).

The intuition behind the increasing equilibrium prices is the following. If $\Delta^{\tau}$ increases (that is a larger $\tau_{2}$ ), for a given market share the incumbent has to face a larger per-consumer access deficit (or smaller access profit); therefore the total access profit can be reduced by decreasing the product of market shares $\left(\alpha_{1} \alpha_{2}\right)$. Since $\alpha_{1} \alpha_{2}$ is smaller if the difference in market shares is larger, the incumbent is interested in moving away from the symmetric case which can be achieved by a higher retail price. The entrant has the same preference over its own price change. The entrant wants to lower the net outflow of calls to raise the per-consumer access profit, which can be obtained by charging a higher retail price. As a consequence the entrant gets higher per-consumer retail profit, and since the incumbent is interested in lowering its market share, the entrant obtains higher total retail profit.

Despite the increasing prices, if $\Delta^{\tau}$ is larger, the entrant with the lower cost receives higher and increasing equilibrium profit, while the incumbent gets lower and decreasing profit. This means that the firms have divergent preferences over the access fee (see Figures 8-10). The industry profit changes in the same direction as the entrant's profit, thus obtaining similar result to Armstrong's: 
the entrant can offer a side-payment for the less efficient firm to compensate for a larger $\Delta^{\tau}$.

Up to now we have analyzed the case of zero brand loyalty. However, where demand side asymmetry exceeds cost asymmetry, the stronger the brand loyalty, the larger the incumbent's retail price and the smaller the entrant's price compared to the case of zero brand loyalty; moreover the prices become monotone decreasing function of $\Delta^{\tau}$. Therefore, the overall effect of increasing $\Delta^{\tau}$ on consumer surplus is positive. As a result of the decreasing prices, not only the incumbent's profit but also the entrant's profit is decreasing, resulting in a lower industry profit. In this case firms have similar preference over the access fee, that is a smaller $\Delta^{\tau}$, which may result in a negative access mark-up for the entrant.

Welfare changes in the same direction as consumer surplus, meaning that under low brand loyalty a larger $\Delta^{\tau}$, otherwise a smaller $\Delta^{\tau}$ is more favorable (see Figure 11).

\section{Linear demand and two-part tariffs}

This section analyzes network interconnection and competition in two-part tariffs. In the symmetric models of Armstrong (1998) and Laffont et al. (1998a), they obtain a profit-neutrality result, i.e. the firms' profit is independent of the access fee and equal to the Hotelling-profit. Since the firms are indifferent over the access fee, the zero access mark-up (i.e. cost-based access fee) which is the socially optimal solution might be carried through. In this section, we look for the equilibrium in the presence of network asymmetry, and answer the question of whether the profit-neutrality property still holds and if not, what the socially preferable access charge would be.

\subsection{Demand structure and consumer surplus}

The consumers' utility and demand functions are the same as those set in Section 3. However in the present model each network offers a two-part tariff, therefore a consumer of network $i$ making $q$ units of call pays

$$
T_{i}(q)=m_{i}+p_{i} q,
$$

where $m_{i}$ is the fixed fee, e.g. the monthly charge of usage, and $p_{i}$ is the per-minute charge. As a consequence, the net surplus a consumer obtains subscribing to network $i$ is equal to

$$
w\left(p_{i}, m_{i}\right)=v\left(p_{i}\right)-m_{i} .
$$

The network shares can be determined by finding the consumer, located in $\alpha$, who is indifferent between the two networks. This indifference means that

$$
w\left(p_{1}, m_{1}\right)-t \alpha+t \beta=w\left(p_{2}, m_{2}\right)-t(1-\alpha) .
$$

From this expression, firm 1's network share is

$$
\hat{\alpha}_{1}(\hat{s})=\frac{1+\beta}{2}+\sigma\left[w\left(p_{1}, m_{1}\right)-w\left(p_{2}, m_{2}\right)\right],
$$


where $\sigma=\frac{1}{2 t}$ is the measure of substitution and $\hat{s}=\left(p_{1}, m_{1}, p_{2}, m_{2}\right)$ is a possible price profile of the firms. Henceforth denote $v_{i} \equiv v\left(p_{i}\right), q_{i} \equiv q\left(p_{i}\right)$, $w_{i} \equiv w\left(p_{i}, m_{i}\right)$ and

$$
\alpha_{1} \equiv \alpha\left(w_{1}, w_{2}\right)=\frac{1+\beta}{2}+\sigma\left(w_{1}-w_{2}\right) .
$$

For a given $\hat{s}$ strategy profile the consumer surplus is the following:

$$
S(\hat{s})=\hat{\alpha}_{1}(\hat{s}) w_{1}+\hat{\alpha}_{2}(\hat{s}) w_{2}-D\left[\hat{\alpha}_{1}(\hat{s})\right],
$$

where $D(\alpha)$ measures the average disutility originating from the difference between the a priori preferences and the characteristics of services.

\subsection{Price competition}

Firm $i$ 's benefits and costs can be read from Figure 1, and the profit is as follows

$$
\pi_{i}(\hat{s})=\hat{\alpha}_{i}(\hat{s})\left[\left(p_{i}-c_{i}\right) q_{i}+m_{i}-f\right]+\hat{\alpha}_{i}(\hat{s}) \hat{\alpha}_{j}(\hat{s})\left[\left(\tau_{i}-c_{i}^{0}\right) q_{j}-\left(\tau_{j}-c_{i}^{0}\right) q_{i}\right] .
$$

To simplify the profit maximization, we rewrite the profit function of firm $i$ using a modified strategy profile $s=\left(p_{1}, w_{1}, p_{2}, w_{2}\right)$. Since with this modification the market share $\alpha_{i}$ is the function of $\left(w_{1}, w_{2}\right)$, the profit function becomes quadratic in $p_{i}$, :

$$
\pi_{i}(s)=\alpha_{i}\left[\left(p_{i}-c_{i}\right) q_{i}+v_{i}-w_{i}-f\right]+\alpha_{i} \alpha_{j}\left[\left(\tau_{i}-c_{i}^{0}\right) q_{j}-\left(\tau_{j}-c_{i}^{0}\right) q_{i}\right] .
$$

Hereafter denote $A_{i} \equiv\left(\tau_{i}-c_{i}^{0}\right) q_{j}-\left(\tau_{j}-c_{i}^{0}\right) q_{i}$ firm $i$ 's per-consumer access profit.

We intend to find the Nash-equilibrium, in which each firm maximizes its profit functions (7) according to its price and the offered net surplus simultaneously, subject to

$$
\begin{aligned}
& 0 \leq p_{i}, \leq 1, \\
& 0 \leq w_{i}, \quad i=1,2 . \\
& 0 \leq \alpha_{i} \leq 1, \\
& 0 \leq \pi_{i}
\end{aligned}
$$

The first order conditions of profit maximization are

$$
\frac{\partial \pi_{i}}{\partial p_{i}}=\alpha_{i}\left[-p_{i}+c_{i}+\alpha_{j}\left(\tau_{j}-c_{i}^{0}\right)\right]=0
$$

and

$$
\frac{\partial \pi_{i}}{\partial w_{i}}=\sigma\left[\left(p_{i}-c_{i}\right) q_{i}+v_{i}-f-w_{i}-\frac{\alpha_{i}}{\sigma}-2 \sigma\left(w_{i}-w_{j}\right) A_{i}\right]=0 .
$$

The first order condition according to $w_{i}$ is quartic, therefore the equilibrium cannot be given in the regular closed form. However, the first order condition according to $p_{i}$ is linear for non-negative market shares; therefore the following proposition can be claimed about the equilibrium and its properties ${ }^{8}$.

\footnotetext{
${ }^{8}$ The proof is given in Appendix A.
} 


\section{Proposition 3 If}

$$
\left|A_{i}\right|<\frac{1}{\sigma}
$$

for $i=1,2$, there is an equilibrium which is unique and characterized as

$$
\begin{gathered}
p_{i}=c_{i}+\alpha_{j}\left(\tau_{j}-c_{i}^{0}\right) \\
m_{i}=f+\frac{\alpha_{i}}{\sigma}-\alpha_{j}\left(\tau_{j}-c_{i}^{0}\right) q_{i}+\left(\alpha_{i}-\alpha_{j}\right) A_{i} \\
\alpha_{1}=\frac{1}{2}+\frac{\beta}{6}+\frac{\sigma}{3}\left[v_{1}-v_{2}+\alpha_{2}\left(\tau_{2}-c_{2}^{0}\right) q_{1}-\alpha_{1}\left(\tau_{1}-c_{1}^{0}\right) q_{2}+\Delta^{c}\left(\alpha_{1} q_{1}+\alpha_{2} q_{2}\right)\right] \\
\pi_{i}=\alpha_{i}^{2}\left[\frac{1}{\sigma}+A_{i}\right] .
\end{gathered}
$$

We get first best retail prices (8) since they are equal to the perceived marginal cost of a unit call, that is the marginal cost of an on-net call $\left(\alpha_{i} 2 c_{i}^{0}\right)$ plus the marginal cost of an off-net call $\left(\alpha_{j}\left(\tau_{j}+c_{i}^{0}\right)\right)$. In this case, each firm sets its retail price as if it maximized the total surplus, therefore the firm behaves as a monopoly over the determination of the fixed fee. Therefore the fixed fee (9) extracts the consumer surplus and covers the fixed cost and is modified (either reduced or raised) with the access profit. If the access profit is high enough, the fixed fee can be negative which can be seen very often in practice. A typical example for this situation is the device subsidy.

\subsection{Comparison and policy implications}

We start comparing the results in case of cost-based access fee and then we extend the analysis to a particular situation when the entrant is allowed to charge a higher access fee than its termination cost $\left(\tau_{2}-c_{2}^{0}>0\right)$.

First we redefine the equilibrium to the case of a cost-based access fee, substituting $\tau_{i}=c_{i}^{0}$, that is

$$
\begin{gathered}
p_{i}=c_{i}+\alpha_{j}\left(c_{j}^{0}-c_{i}^{0}\right), \\
m_{i}=f+\alpha_{i}\left[\frac{1}{\sigma}-\left(c_{j}^{0}-c_{i}^{0}\right) q_{i}\right], \\
\alpha_{1}=\frac{1}{2}+\frac{\beta}{6}+\frac{\sigma}{3}\left[v_{1}-v_{2}+\Delta^{c}\left(\alpha_{1} q_{1}+\alpha_{2} q_{2}\right)\right], \\
\pi_{i}=\alpha_{i}^{2}\left[\frac{1}{\sigma}-\left(c_{j}^{0}-c_{i}^{0}\right) q_{i}\right] .
\end{gathered}
$$

For the comparison denote $\Delta^{p} \equiv p_{2}-p_{1}, \Delta^{q} \equiv q_{2}-q_{1}, \Delta^{v} \equiv v_{2}-v_{1}, \Delta^{m} \equiv$ $m_{2}-m_{1}, \Delta^{\alpha} \equiv \alpha_{2}-\alpha_{1}$ and $\Delta^{\pi} \equiv \pi_{2}-\pi_{1}$. The difference between the equilibrium per-minute prices is equal to the cost difference $\left(\Delta^{p}=\Delta^{c}\right)$, i.e. the incumbent with the larger cost charges a larger per-minute price. As a consequence, the consumers of the incumbent initiate less calls $\left(\Delta^{q}=-\Delta^{c}\right)$ thus obtaining lower net surplus. When the entrant's access fee increases, firm 1's perceived marginal cost increases, therefore it sets a more higher per-minute price $\left(\Delta^{p}=\Delta^{c}-\alpha_{2}\left(\tau_{2}-c_{2}^{0}\right)<0\right)$. 
Since each firm charges its perceived marginal cost as a retail price, it gets zero profit from calls originating in its network; therefore the profit arises from the connection dependent profit and from the incoming calls. The difference in equilibrium profits is closely related to the difference in fixed fees, which in the case of a cost-based access fee is equal to

$$
\Delta^{m}=\frac{\Delta^{\alpha}}{\sigma}+\Delta^{c}\left(\alpha_{1} q_{1}+\alpha_{2} q_{2}\right) .
$$

This expression can be either negative or positive, and since the second part of (11) is always negative, the sign of (11) depends on which firm has a larger market share.

As for the market shares, the difference varies in response to the strength of brand loyalty and the cost difference in the following way:

$$
\Delta^{\alpha}=\frac{-\beta-4 \sigma \Delta^{c}\left(1-\alpha_{1} c_{1}-\alpha_{2} c_{2}\right)}{3+\sigma\left(\Delta^{c}\right)^{2}} .
$$

The denominator of (12) is always positive, and therefore the entrant has a higher market share only if the numerator is also positive. Let us start from zero cost difference. In case of symmetric costs only brand loyalty has an effect on market shares, and in spite of its higher per-minute price, the incumbent obtains higher market share $\left(\Delta^{\alpha}=-\beta / 3<0\right)$. If $\Delta^{\alpha}<0$ and $\Delta^{c}=0$, then $\Delta^{m}<0$, meaning that the incumbent sets a higher fixed fee. The behavior of firm 1 is straightforward: it faces a positive per-consumer access profit; therefore it can increase its total access profit by raising the product of market shares $\left(\alpha_{1} \alpha_{2}\right)$. This product is maximal if firms are symmetric, that is $\alpha_{1} \alpha_{2}=1 / 4$. Firm 1 can enlarge this product by reducing its (larger) market share by means of a higher access fee.

In case of zero brand loyalty, for reasonably low termination costs $\left(\alpha_{1} c_{1}^{0}+\right.$ $\alpha_{2} c_{2}^{0}<1$ ), the numerator of (12) is positive, causing higher market share for the entrant $\left(\Delta^{\alpha}=-4 \sigma \Delta^{c}\left(1-\alpha_{1} c_{1}-\alpha_{2} c_{2}\right) /\left(3+\sigma\left(\Delta^{c}\right)^{2}\right)>0\right)$. The intuition is similar to the linear pricing case. Since the entrant faces a negative perconsumer access profit, it is interested in lowering the total access profit and raising the total retail profit, that is moving further from the symmetric case through a higher market share. A higher market share can be obtained by simply setting a lower price or by charging a lower fixed fee at the same time. Therefore if $\beta=0$, it is not obvious which firm sets a higher fixed fee: $\Delta^{m}$ depends on how cost difference and brand loyalty relate to each other. For a given brand loyalty, the larger the cost difference, the higher the entrant's market share and the more likely that it charges a higher fixed fee.

The same argument can be applied to the difference between $\pi_{2}$ and $\pi_{1}$ which is equal to

$$
\Delta^{\pi}=\frac{\Delta^{\alpha}}{\sigma}+\Delta^{c}\left(\alpha_{1}^{2} q_{1}+\alpha_{2}^{2} q_{2}\right)
$$

If the entrant can slightly deviate from the cost-based access fee, a small access mark-up does not affect the equilibrium market shares ${ }^{9}$, therefore the above results remain unchanged.

In a neighborhood of cost-based access fee $\partial \alpha_{i} / \partial \tau_{2}=0$ holds. Applying this shows that the effect of the increment in $\tau_{2}$ on equilibrium profits can be

\footnotetext{
${ }^{9}$ The proof is similar to lemma 1's proof in Peitz (2005), p. 356.
} 
measured by the following derivatives:

$$
\begin{gathered}
\left.\frac{\partial \pi_{1}}{\partial \tau_{2}}\right|_{\tau_{2}=c_{2}^{0}}=\alpha_{1}^{2}\left(\alpha_{2} \Delta^{c}-q_{1}\right)<0, \\
\left.\frac{\partial \pi_{2}}{\partial \tau_{2}}\right|_{\tau_{2}=c_{2}^{0}}=\alpha_{2}^{2} q_{1}>0 .
\end{gathered}
$$

Using these expressions, we state that profit-neutrality of the symmetric equilibrium no longer holds: the incumbent's profit decreases and the entrant's profit increases in response to an increase in $\tau_{2}$. If the termination costs are the same, then each firm's profit depends solely on its market share. Therefore the industry profit changes in the same direction as that of the larger firm, which is in this case the incumbent. The larger the cost difference, the larger the entrant's market share, thus the more likely that the industry profit varies in the same direction as the entrant's profit. As a consequence, we find that in case of zero cost difference, the access mark-up favors the entrant, and for a larger cost difference it favors the industry also.

As Peitz (2005) claims in case of symmetric costs, the consumer surplus increases as the entrant is allowed to use an access mark-up. This result holds true if the cost difference remains small: an increase in $\tau_{2}$ is followed by a larger consumer surplus, though the consumer surplus is lower than that of zero cost difference. However for large cost differences the consumers are worse off.

The previous results are summarized in the following proposition ${ }^{10}$ :

Proposition 4 In case of symmetric costs, in a neighborhood around cost-based access prices an increase in the entrant's access price gives rise to higher profit for the entrant and higher consumer surplus. With increasing cost differences, the industry profit might also increase though it leads to a smaller consumer surplus.

\section{Conclusions}

In the present paper, we analyzed network interconnection and competition under two different types of asymmetry, namely a demand side advantage emerging from the incumbent's stronger reputation or the lack of information about the entrant's servicing quality and a supply side advantage, that is the entrant's lower marginal cost. In contrast to the symmetric model, in most cases the firms have divergent preferences over the access fee difference. As preceding papers show, in case of a demand side asymmetry, a firm which entered the market later might set an access fee larger than its termination cost thus resulting a higher profit and consumer surplus. Emphasizing a stronger supply side asymmetry, we find that a positive access markup can make the consumers worse off.

As the results show, the access fee regulated on the basis of termination cost might not necessarily provide the socially preferable solution. In case of an infant market, when the incumbent derives advantage from earlier presence in

\footnotetext{
${ }^{10}$ The proof is given in Appendix A.
} 
the market, an access mark-up for the entrant may increase consumer surplus and welfare. However in a more symmetric market when the importance of the incumbent's reputation is eliminated, a cost-based access fee or even a negative mark-up for the entrant might provide a socially optimal outcome. As for the implementation of these results, it would be required to report precisely the costs and have a reliable estimate for the incumbent's advantage.

This paper presented a model for mobile telephony where operators have full coverage. The two-way access pricing is also applicable in local telecommunications and in the dynamically developing Internet market. However in these markets operators do not always establish their own network therefore they provide services through the rivals' bottlenecks. In these cases an analysis extended to other types of entry, namely local-loop unbundling and carrier select, would refine the results and their policy implications.

\section{Appendices}

\section{A Proofs}

Proof of Proposition 1. Existence and uniqueness of the equilibrium.

The first order condition for firm $i$ is

$\frac{\partial \pi_{i}}{\partial p_{i}}=-\sigma\left(p_{i}-C_{i}\right)+\left(\frac{1 \pm \beta}{2}+\sigma\left(p_{j}-p_{i}\right)\right)+\sigma\left[2 \sigma\left(p_{j}-p_{i}\right) \pm \beta\right]\left(\tau_{i}-\tau_{j}\right)=0$,

where the upper sign of $\beta$ applies to firm 1, and the lower to firm 2. From this first order condition firm $i$ 's reaction curve is

$$
\begin{aligned}
& r_{1}\left(p_{2}\right)=\frac{\left(1+2 \sigma\left(\tau_{1}-\tau_{2}\right)\right) p_{2}+C_{1}+(1+\beta) / 2 \sigma-\beta \Delta^{\tau}}{2\left(1+\sigma\left(\tau_{1}-\tau_{2}\right)\right)}, \\
& r_{2}\left(p_{1}\right)=\frac{\left(1+2 \sigma\left(\tau_{2}-\tau_{1}\right)\right) p_{1}+C_{2}+(1-\beta) / 2 \sigma-\beta \Delta^{\tau}}{2\left(1+\sigma\left(\tau_{2}-\tau_{1}\right)\right)} .
\end{aligned}
$$

Since

$$
\frac{\partial r_{i}}{\partial p_{j}}=\frac{1+2 \sigma\left(\tau_{i}-\tau_{j}\right)}{2\left(1+\sigma\left(\tau_{i}-\tau_{j}\right)\right)},
$$

each reaction curve is a monotonic function of the rival firm's price (that is firms are strategic complements) if and only if

$$
\tau_{j}-\tau_{i}<\frac{1}{2 \sigma} .
$$

Moreover the slope of the reaction function is constant and $0<r_{i}^{\prime}(\cdot)<1$ holds. Therefore the reaction curves intersect only once in the relevant price range and a unique equilibrium exists. The second derivatives are the following

$$
\frac{\partial^{2} \pi_{i}}{\partial p_{i}^{2}}=-2 \sigma\left(1+\sigma\left(\tau_{i}-\tau_{j}\right)\right)<0
$$

for $i=1,2$, which are negative if (13) holds. In this case the profit function is strictly quasi-concave, so therefore it has a unique maximum. 
From the reaction curves the equilibrium prices, market shares and maximal profits can be derived as follows:

$$
\begin{gathered}
p_{1}^{*}=\frac{1}{2 \sigma}+\frac{\beta}{6 \sigma}+\frac{2 C_{1}+C_{2}}{3}-\frac{\Delta^{\tau}}{3}\left(\beta+4 \sigma \Delta^{c}\right) \\
p_{2}^{*}=\frac{1}{2 \sigma}-\frac{\beta}{6 \sigma}+\frac{2 C_{2}+C_{1}}{3}-\frac{\Delta^{\tau}}{3}\left(\beta+4 \sigma \Delta^{c}\right) \\
\alpha_{1}^{*}=\frac{1}{2}+\frac{1}{6}\left(\beta+4 \sigma \Delta^{c}\right) \\
\pi_{i}^{*}=\left(\alpha_{i}^{*}\right)^{2}\left[\frac{1}{\sigma}+\tau_{i}-\tau_{j}\right]
\end{gathered}
$$

If (13) holds, the equilibrium prices and profits are positive.

Shared- or cornered-market outcome. (I) Suppose that firm 1 corners the market and sets a low price such that (i) at this price the closest consumer to firm 2 also wants to buy from firm 1 , that is

$$
v_{0}+\frac{\beta}{2 \sigma}-\frac{1}{2 \sigma}-p_{1} \geq v_{0}-p_{2},
$$

and (ii) this price is a Nash-equilibrium price, since none of the firms wants to unilaterally deviate from it. Substituting (14) and (15) into (16), we get the condition for a cornered-market, that is

$$
\beta+4 \sigma \Delta^{c} \geq 3
$$

Since $\Delta^{c}<0$ and $\sigma>0$, this condition holds if $\beta>>3$. In this case firm 1 gets positive profit, and firm 2 gets zero since it does not have any subscribers. If firm 2 attempts to mimic firm 1 with the same price, it will achieve a positive market share, but receives negative per-consumer profit. Therefore it is not profitable to deviate from the equilibrium.

(II) Suppose now that only firm 2 attains subscribers. It can be possible for an equilibrium price $p_{2}$ which satisfies the following condition:

$$
v_{0}+\frac{\beta}{2 \sigma}-p_{1} \leq v_{0}-\frac{1}{2 \sigma}-p_{2}
$$

This condition in the equilibrium holds if and only if

$$
\beta+4 \sigma \Delta^{c} \leq-3
$$

that is $4 \sigma\left|\Delta^{c}\right|>>3$. We can now follow the same argument as in point (I).

(III) If

$$
\left|\beta+4 \sigma \Delta^{c}\right|<3
$$

then the equilibrium market shares are positive, i.e. the shared market outcome emerges.

Proof of Proposition 3. Suppose that profit function (7) is twice continuously differentiable. The first order conditions of profit maximizations are

$$
\frac{\partial \pi_{i}}{\partial p_{i}}=\alpha_{i}\left[-p_{i}+c_{i}+\alpha_{j}\left(\tau_{j}-c_{i}^{0}\right)\right]=0
$$


and

$$
\frac{\partial \pi_{i}}{\partial w_{i}}=\sigma\left[\left(p_{i}-c_{i}\right) q_{i}+v_{i}-f-w_{i}-\frac{\alpha_{i}}{\sigma}-2 \sigma\left(w_{i}-w_{j}\right) A_{i}\right]=0,
$$

where $A_{i}=\left(\tau_{i}-c_{i}^{0}\right) q_{j}-\left(\tau_{j}-c_{i}^{0}\right) q_{i}$ is firm $i$ 's per-consumer access profit. From these conditions we get the equilibrium values stated in the proposition:

$$
\begin{gathered}
p_{i}=c_{i}+\alpha_{j}\left(\tau_{j}-c_{i}^{0}\right) \\
m_{i}=f+\frac{\alpha_{i}}{\sigma}-\alpha_{j}\left(\tau_{j}-c_{i}^{0}\right) q_{i}+\left(\alpha_{i}-\alpha_{j}\right) A_{i}, \\
\alpha_{1}=\frac{1}{2}+\frac{\beta}{6}+\frac{\sigma}{3}\left[v_{1}-v_{2}+\alpha_{2}\left(\tau_{2}-c_{2}^{0}\right) q_{1}-\alpha_{1}\left(\tau_{1}-c_{1}^{0}\right) q_{2}\right. \\
\left.+\Delta^{c}\left(\alpha_{1} q_{1}+\alpha_{2} q_{2}\right)\right], \\
\pi_{i}=\alpha_{i}^{2}\left[\frac{1}{\sigma}+A_{i}\right] .
\end{gathered}
$$

For the existence of the equilibrium, the following second order conditions (SOCs) should hold:

(i)

$$
\frac{\partial^{2} \pi_{i}}{\partial p_{i}^{2}}=-\alpha_{i}<0
$$

which holds if $\alpha_{i}>0$ and $\partial^{2} \pi_{i} / \partial p_{i}^{2}=0$ if firm $j$ corners the market.

(ii)

$$
\frac{\partial^{2} \pi_{i}}{\partial w_{i}^{2}}=-2 \sigma\left(1+\sigma A_{i}\right)<0 \Leftrightarrow\left|A_{i}\right|<\frac{1}{\sigma}
$$

This expression states that the SOC according to $w_{i}$ holds if and only if for a given $\sigma$ the per-consumer access profit is small enough or if $\sigma$ is small so that there is weak substitution between the networks.

(iii) Since

$$
\frac{\partial^{2} \pi_{i}}{\partial p_{i} \partial w_{i}}=\frac{\partial^{2} \pi_{i}}{\partial w_{i} \partial p_{i}}=-\sigma \alpha_{i}\left(\tau_{j}-c_{i}^{0}\right)
$$

therefore

$$
\frac{\partial^{2} \pi_{i}}{\partial p_{i}^{2}} \frac{\partial^{2} \pi_{i}}{\partial w_{i}^{2}}>\left(\frac{\partial^{2} \pi_{i}}{\partial p_{i} \partial w_{i}}\right)^{2} \Leftrightarrow \alpha_{i}\left(\tau_{j}-c_{i}^{0}\right)^{2}<2\left(\frac{1}{\sigma}+A_{i}\right) .
$$

This condition holds if brand loyalty is not very strong and $\tau_{i}$ is close to $c_{i}^{0}$ which allows only a small access market.

Proof of Proposition 4. The structure of the proof originates in Peitz (2005) who applied the methodology of supermodular games and monotone comparative statics of the equilibrium.

Assume that firm 1 is subject to cost-based access fee, and firm 2 can freely set its access charge. Substituting the equilibrium prices (10) into the modified profit function (7) we find a pseudo-profit function:

$$
\hat{\pi}_{i}\left(w_{1}, w_{2}, p_{j}\right)=\alpha_{i}\left(v\left[c_{i}+\alpha_{j}\left(\tau_{j}-c_{i}^{0}\right)\right]-w_{i}-f+\alpha_{j}\left(\tau_{i}-c_{i}^{0}\right) q_{j}\right)
$$


from which the first derivative according to $w_{i}$ is

$$
\begin{aligned}
\frac{\partial \hat{\pi}_{i}}{\partial w_{i}}= & \sigma\left(v\left[c_{i}+\alpha_{j}\left(\tau_{j}-c_{i}^{0}\right)\right]-w_{i}-f+\alpha_{j}\left(\tau_{i}-c_{i}^{0}\right) q_{j}\right) \\
& +\alpha_{i}\left(\sigma\left(\tau_{j}-c_{i}^{0}\right) q\left[c_{i}+\alpha_{j}\left(\tau_{j}-c_{i}^{0}\right)\right]-1-\sigma\left(\tau_{i}-c_{i}^{0}\right) q_{j}\right) .
\end{aligned}
$$

If the second derivative according to $w_{j}$ is positive, the slope of the pseudoreaction curve is positive (i.e. strategic complements), and if the second derivative according to $\tau_{2}$ is also positive, the reaction curve moves outward in response to an increase in $\tau_{2}$, which means that the net equilibrium surplus increases with $\tau_{2}$.

First consider the first derivative of firm 1's pseudo-profit:

$$
\begin{aligned}
\frac{\partial \hat{\pi}_{1}}{\partial w_{1}}= & \sigma\left(v\left[c_{1}+\alpha_{2}\left(\tau_{2}-c_{1}^{0}\right)\right]-w_{1}-f\right) \\
& +\alpha_{1}\left(\sigma\left(\tau_{2}-c_{1}^{0}\right) q\left[c_{1}+\alpha_{2}\left(\tau_{2}-c_{1}^{0}\right)\right]-1\right) .
\end{aligned}
$$

The second derivative according to $w_{2}$ is equal to

$$
\frac{\partial^{2} \hat{\pi}_{1}}{\partial w_{1} \partial w_{2}}=\sigma\left(1-\sigma\left(\tau_{2}-c_{1}^{0}\right) q\left[c_{1}+\alpha_{2}\left(\tau_{2}-c_{1}^{0}\right)\right]\right) .
$$

If the access mark-up is small so that $c_{2}^{0}<\tau_{2}<c_{1}^{0}$, then the cross-derivative is positive, which means that firm 1's best response function is upward sloping. This is also the case if $\tau_{2}<c_{2}^{0}<c_{1}^{0}$ (there is a negative mark-up). A sufficient condition for strategic complements is that $\tau_{2}<c_{1}^{0}$.

As for the other second derivative,

$$
\frac{\partial^{2} \hat{\pi}_{1}}{\partial w_{1} \partial \tau_{2}}=-\sigma\left(\Delta^{\alpha} q\left[c_{1}+\alpha_{2}\left(\tau_{2}-c_{1}^{0}\right)\right]+\alpha_{1} \alpha_{2}\left(\tau_{2}-c_{1}^{0}\right)\right)
$$

is positive if $\tau_{2}<c_{1}^{0}$ and $\Delta^{\alpha}$ is negative: that is, the incumbent has a larger market share. This can occur in case of small cost difference and strong brand loyalty:

$$
\beta+4 \sigma \Delta^{c}\left(1-\alpha_{1} c_{1}-\alpha_{2} c_{2}\right)>0 .
$$

In this case firm 1's reaction curve moves outward, therefore its consumers benefit from a larger $\tau_{2}$.

Consider now firm 2's first derivative function:

$$
\begin{aligned}
\frac{\partial \hat{\pi}_{2}}{\partial w_{2}}= & \sigma\left(v\left[c_{2}-\alpha_{1} \Delta^{c}\right]-w_{2}-f+\alpha_{1}\left(\tau_{2}-c_{2}^{0}\right) q_{1}\right) \\
& -\alpha_{2}\left(\sigma \Delta^{c} q\left[c_{2}-\alpha_{1} \Delta^{c}\right]+1+\sigma\left(\tau_{2}-c_{2}^{0}\right) q_{1}\right) .
\end{aligned}
$$

The cross-derivative according to $w_{1}$ is equal to

$$
\frac{\partial^{2} \hat{\pi}_{2}}{\partial w_{2} \partial w_{1}}=\sigma\left(\sigma \Delta^{c}\left(q_{1}+q\left[c_{2}-\alpha_{1} \Delta^{c}\right]-\alpha_{2}\right)+2 \sigma\left(\tau_{2}-c_{2}^{0}\right) q_{1}+1\right),
$$

which is positive - in the neighborhood of cost-based access fee - if the cost difference is small:

$$
\left|\Delta^{c}\right|<\frac{2\left(\tau_{2}-c_{2}^{0}\right) q_{1}+\frac{1}{\sigma}}{q_{1}+q\left[c_{2}-\alpha_{1} \Delta^{c}\right]-\alpha_{2}} .
$$


The second derivative according to $\tau_{2}$ is equal to

$$
\frac{\partial^{2} \hat{\pi}_{2}}{\partial w_{2} \partial \tau_{2}}=-\sigma \Delta^{\alpha} q_{1}
$$

which is positive if the cost difference is small and brand loyalty is strong. The larger the cost difference, the more likely the reaction curve moves inward.

As can be seen from (17) and (18)

$$
\left|\frac{\partial^{2} \hat{\pi}_{1}}{\partial w_{1} \partial \tau_{2}}\right|<\left|\frac{\partial^{2} \hat{\pi}_{2}}{\partial w_{2} \partial \tau_{2}}\right|,
$$

it is more likely that firm 1's reaction curve moves inward. The overall effect of $\tau_{2}$ on the consumer surplus depends on the size of $\Delta^{\alpha}$. If $\Delta^{\alpha}>0$, both reaction curves move inward thus lowering the total consumer surplus. If $\Delta^{\alpha}<0$, but $\left|\Delta^{\alpha}\right|<\alpha_{1} \alpha_{2}\left(\tau_{2}-c_{1}^{0}\right) / q_{1}$, only firm 1's reaction curve moves inward, and the effect of $\tau_{2}$ on $w_{2}$ is always positive, though its effect on $w_{1}$ is ambiguous: $w_{1}$ can be lower or higher. However if $\Delta^{\alpha}<0$ and $\left|\Delta^{\alpha}\right|>\alpha_{1} \alpha_{2}\left(\tau_{2}-c_{1}^{0}\right) / q_{1}$, both reaction curves move outward yielding higher net surplus for every consumer. 


\section{B Simulation results}

In this section we show some results from simulations: first we illustrate a comparison for different substitution and cost differences, then for different access fees.

\section{B.1 Comparison according to parameter values}

In the following figures we present equilibrium profits (individual and industry, $\pi_{i}$ and $\pi \equiv \pi_{1}+\pi_{2}$ respectively), consumer surplus $(S)$ and welfare $(W \equiv \pi+S)$ for different values of the substitution parameter $(\sigma)$, and for decreasing difference in termination costs $\left(\Delta^{c}\right)$ by different brand loyalty $(\beta)$. For simplicity we assume that the firms are subject to an access fee on the basis of termination cost.

The effect of increasing strength of substitution:

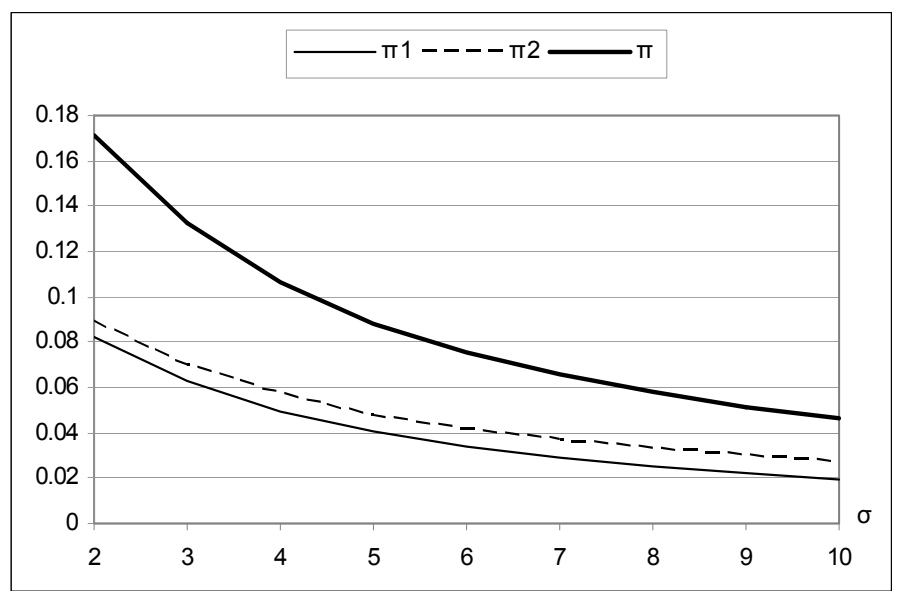

Figure 2. Maximal individual and industry profit, increasing $\sigma$

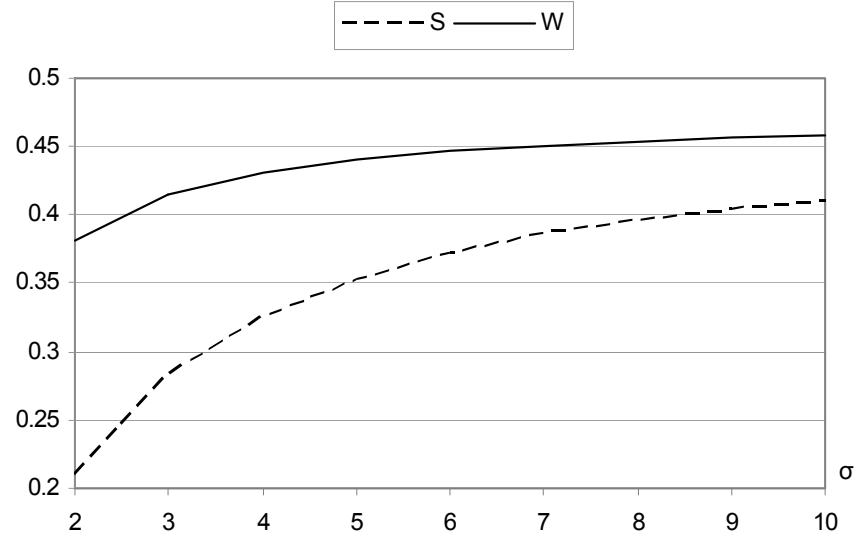

Figure 3. Consumer surplus and social welfare, increasing $\sigma$ 
The effect of decreasing cost difference for different levels of brand loyalty (grey curves show cases of $\beta=0$, and black curves of $\beta=.5$ ):

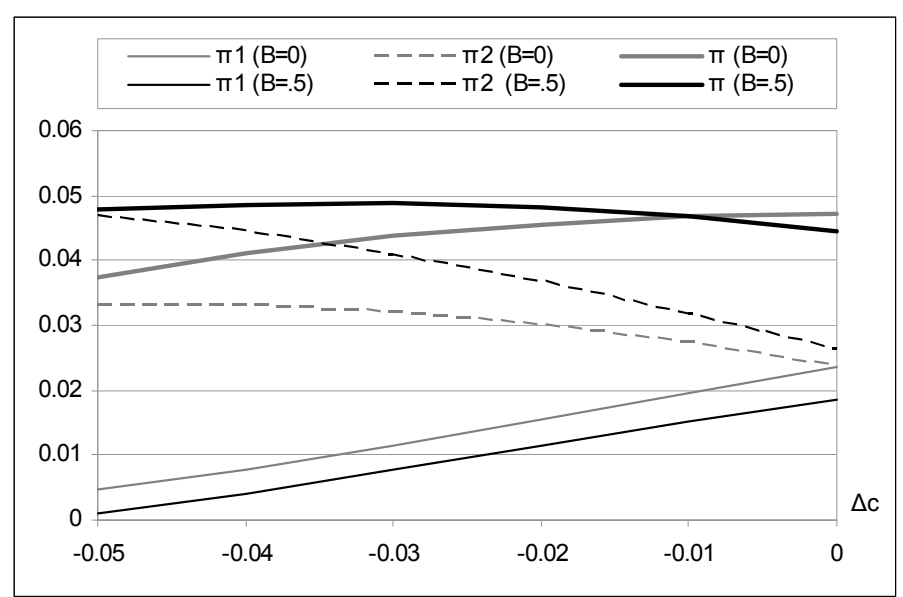

Figure 4. Maximal individual and industry profit, decreasing $\left|\Delta^{c}\right|$

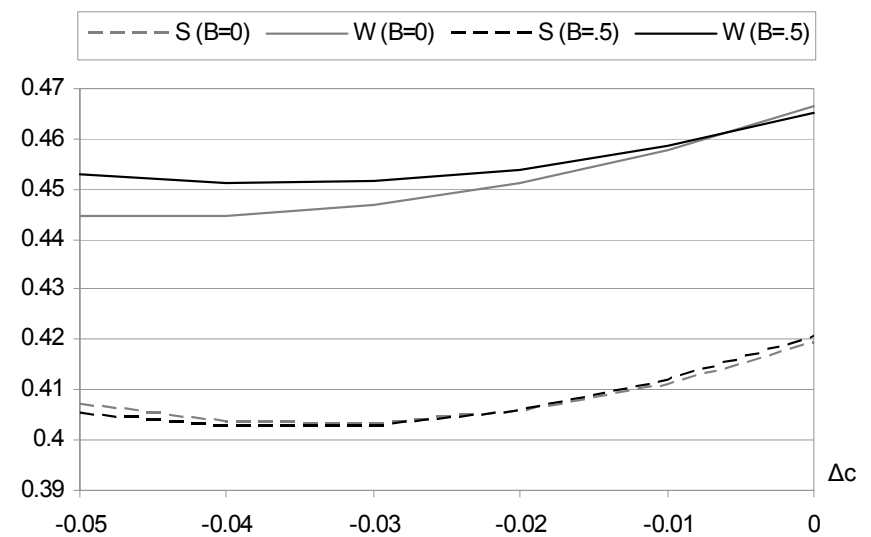

Figure 5. Consumer surplus and social welfare, decreasing $\left|\Delta^{c}\right|$

\section{B.2 Comparison according to access fee}

To compare the effect of different access fees, we fixed the following parameter values

$$
c_{1}^{0}=0.02, c_{2}^{0}=0.01, \sigma=10, f=0, \tau_{1}=0.02 .
$$

In this case, the more efficient firm sets a cost-based access fee, and only firm 2 's access fee is changing. If $\Delta^{\tau}=0$, then the access fees are reciprocal, and if $\Delta^{\tau}=-0,01$, both firms set a cost-based access fee. In the following figures equilibrium prices $\left(p_{i}^{*}\right)$, consumer surplus $(S)$, profits (individual and industry, $\pi_{i}$ and $\pi \equiv \pi_{1}+\pi_{2}$ respectively) and social welfare $(W)$ are shown by different values of brand loyalty $(\beta)$. In the figures we indicate $\Delta^{\tau}$ on the horizontal axis and the above mentioned equilibrium values on the vertical axis. 


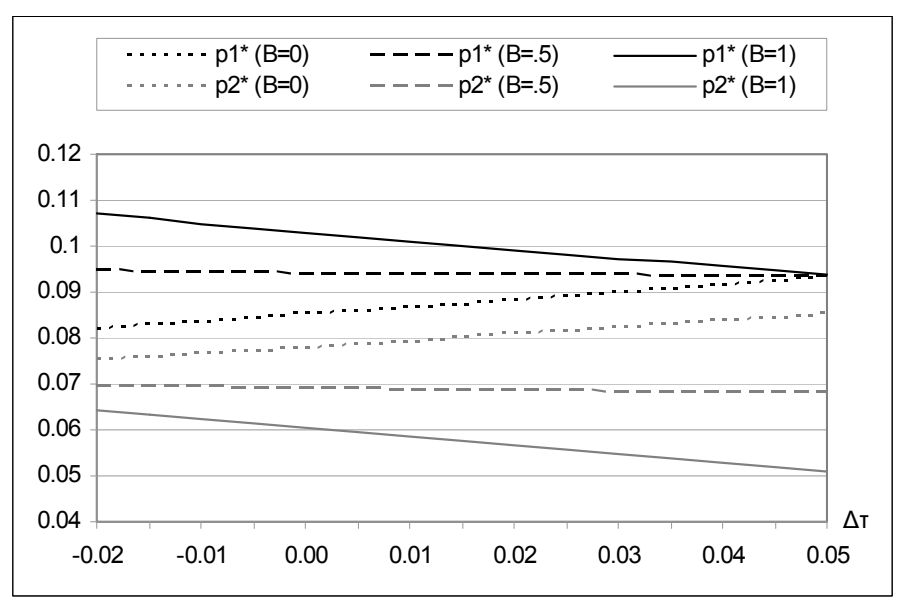

Figure 6. Equilibrium prices, increasing $\Delta^{\tau}$

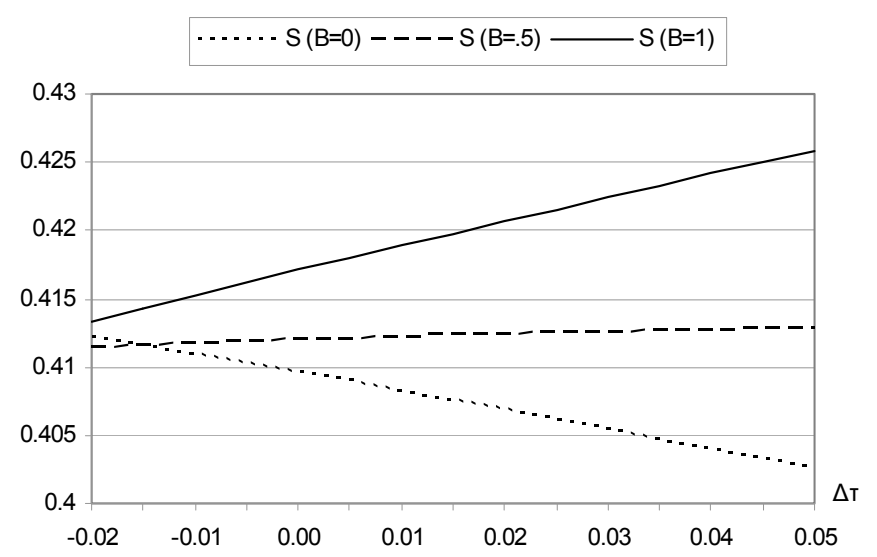

Figure \%. Consumer surplus, increasing $\Delta^{\tau}$

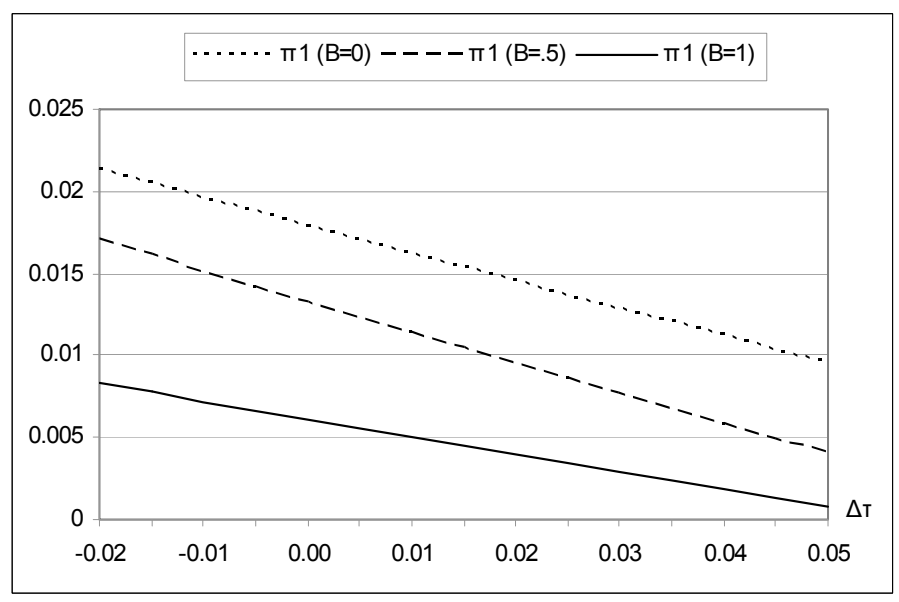

Figure 8. Maximal profit of firm 1, increasing $\Delta^{\tau}$ 


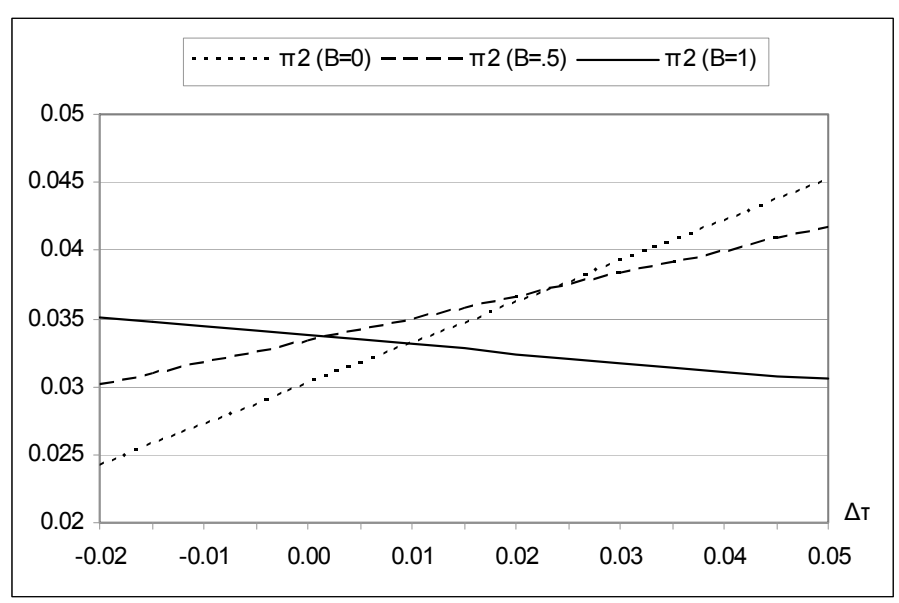

Figure 9. Maximal profit of firm 2, increasing $\Delta^{\tau}$

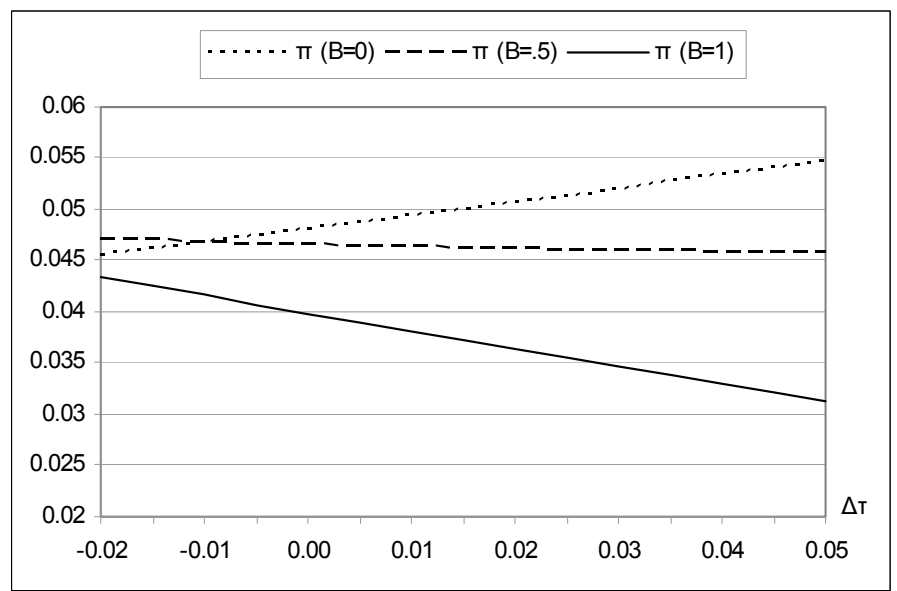

Figure 10. Maximal industry profit, increasing $\Delta^{\tau}$

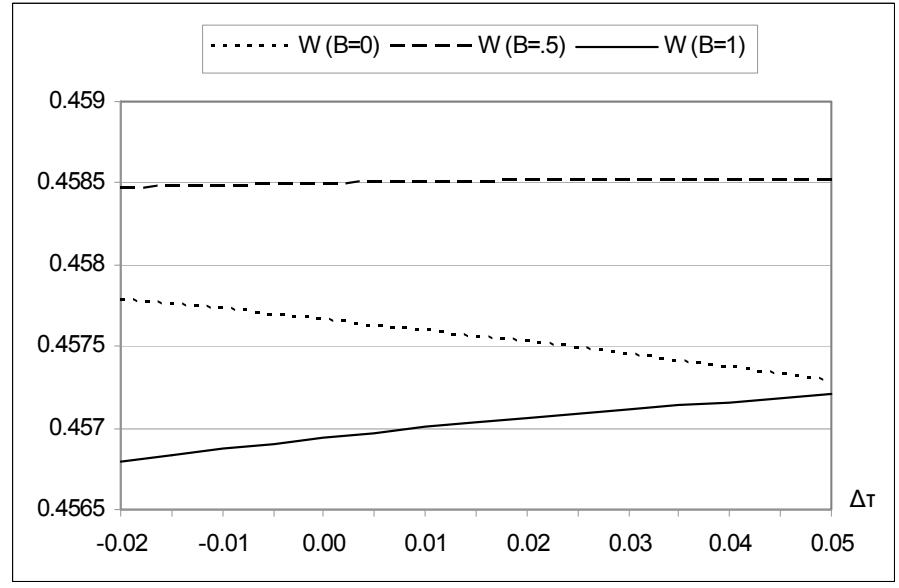

Figure 11. Social welfare, increasing $\Delta^{\tau}$ 


\section{References}

Armstrong, M. (1998). Network interconnection in telecommunications. The Economic Journal 108(448), 545-564.

Armstrong, M. (2002). The theory of access pricing and interconnection. In: Cave, M., Majumdar, S., Vogelsang, I. (Eds.), Handbook of Telecommunications Economics, Vol 1. Elsevier Science Publisher, 295-384.

Carter, M. and J. Wright (1999). Interconnection in network industries. Review of Industrial Organization 14(1), 1-25.

Carter, M. and J. Wright (2003). Asymmetric network interconnection. Review of Industrial Organization 22(1), 27-46.

de Bijl, P. and M. Peitz (2002). Regulation and Entry Into Telecommunications Markets. Cambridge University Press.

de Bijl, P. and M. Peitz (2004). Dynamic regulation and entry in telecommunications markets: A policy framework. Information Economics and Policy 16, 411-437.

Dessein, W. (2004). Network competition with heterogeneous customers and calling patterns. Information Economics and Policy 16, 323-345.

Gruber, H. (2001). Competition and innovation the diffusion of mobile telecommunications in Central and Eastern Europe. Information Economics and Policy 13, 19-34.

Gruber, H. and F. Verboven (2001). The diffusion of mobile telecommunications services in the European Union. European Economic Review 45, $577-588$.

Hahn, J.-H. (2004). Network competition and interconnection with heterogeneous subscribers. International Journal of Industrial Organization 22, 611-631.

Hotelling, H. (1929). Stability in competition. Economic Journal 39, 41-57.

Laffont, J.-J., P. Rey, and J. Tirole (1998a). Network competition: I. Overview and nondiscriminatory pricing. The RAND Journal of Economics 29(1), 1-37.

Laffont, J.-J., P. Rey, and J. Tirole (1998b). Network competition: II. Price discrimination. The RAND Journal of Economics 29(1), 38-56.

Ofcom (2004). Wholesale mobile voice call termination. Statement. www.ofcom. org.uk.

Peitz, M. (2005). Asymmetric access price regulation in telecommunications markets. European Economic Review 49, 341-358.

Vega-Redondo, F. (2003). Economics and the Theory of Games. Cambridge University Press. 